This item was submitted to Loughborough's Research Repository by the author.

Items in Figshare are protected by copyright, with all rights reserved, unless otherwise indicated.

\title{
Unpacking tasks: the fusion of new technology with instructional work
}

PLEASE CITE THE PUBLISHED VERSION

http://dx.doi.org/10.1007/s10606-007-9068-x

PUBLISHER

(C) Springer

VERSION

AM (Accepted Manuscript)

LICENCE

CC BY-NC-ND 4.0

REPOSITORY RECORD

Greiffenhagen, Christian. 2019. "Unpacking Tasks: The Fusion of New Technology with Instructional Work". figshare. https://hdl.handle.net/2134/14210. 
This item was submitted to Loughborough's Institutional Repository (https://dspace.lboro.ac.uk/) by the author and is made available under the following Creative Commons Licence conditions.

\section{creative
commons}

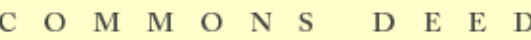

Attribution-NonCommercial-NoDerivs 2.5

You are free:

- to copy, distribute, display, and perform the work

Under the following conditions:

Attribution. You must attribute the work in the manner specified b the author or licensor.

Noncommercial. You may not use this work for commercial purposes.

No Derivative Works. You may not alter, transform, or build upon this work.

- For any reuse or distribution, you must make clear to others the license terms of this work.

- Any of these conditions can be waived if you get permission from the copyright holder.

Your fair use and other rights are in no way affected by the above.

This is a human-readable summary of the Leqal Code (the full license).

\section{Disclaimer 만}

For the full text of this licence, please go to: http://creativecommons.org/licenses/by-nc-nd/2.5/ 


\title{
Unpacking Tasks:
}

\section{the fusion of new technology with instructional work}

\author{
Christian Greiffenhagen
}

Version: January 3, 2007

\begin{abstract}
This paper discusses how a new technology (designed to help pupils with learning about Shakespeare's Macbeth) is introduced and integrated into existing classroom practices. It reports on the ways through which teachers and pupils figure out how to use the software as part of their classroom work. Since teaching and learning in classrooms are achieved in and through educational tasks (what teachers instruct pupils to do) the analysis explicates some notable features of a particular task (storyboarding one scene from the play). It is shown that both 'setting the task' and 'following the task' have to be locally and practically accomplished and that tasks can operate as a sense-making device for pupils' activities. Furthermore, what the task 'is', is not entirely established through the teacher's initial formulation, but progressively clarified through pupils' subsequent work, and in turn ratified by the teacher.
\end{abstract}

Greiffenhagen, C. (2008). Unpacking tasks: the fusion of new technology with instructional work. Computer Supported Cooperative Work (CSCW) 17 (1), 35-62. 


\section{Introduction}

This paper discusses the embedding of a new technology into existing teaching and learning practices. This theme is illustrated through a detailed analysis of how a new storyboarding software (designed to help pupils learn about Shakespeare’s Macbeth) was introduced and integrated into classroom exercises and the ways in which teachers and pupils figured out how to organise its application as part of their educational work.

The data is in many respects unremarkable, but is used here to illustrate the way in which educational purposes and tasks do not necessarily exist in advance of the work to be done, but are construed and produced by participants reflexively in and through their engagement with the new technology and their evolving assumptions about what it is that the task might consist in. Learning the task and learning the technology are mutually constitutive for both teacher and students. The data serves to unpack what 'setting a task' and 'following a task' consist of as practical accomplishments. The organisation of teaching and learning are things done by teachers and pupils as they encounter the technology together for the first time.

The analytic approach to tasks presented here is not to be understood as 'task analysis' (see, e.g., Diaper, 1989; Annett and Stanton, 2000). For the latter, tasks consist of a hierarchy of goals and means, in which any given technology would be seen as the means to achieve the task, quite separate from the goals which constitute it:

Task analysis means the breakdown of overall tasks, as given, into their elements, and the specification of how these elements

Greiffenhagen, C. (2008). Unpacking tasks: the fusion of new technology with instructional work. Computer Supported Cooperative Work (CSCW) 17 (1), 35-62. 
relate to one another in space and time and functional relation.

(Sheridan, 1997, p.87)

In such studies, the delineation of tasks is the outcome of analysis, i.e., a product of the analyst's methods. This study takes a different approach ${ }^{1}$. Tasks are conceived of as oriented-to and achieved phenomena, i.e., as defined in and through participants' activities (and it is a contingent matter as to whether parties attempt to construct a plan of things to be done in advance of undertaking them, or whether they set out on the task with only a vague idea of what is to be done and then figure out, in the doing, what it is that they need to be doing and how they are to do it). How participants enact activities as 'tasked' or 'task related' then becomes the topic of the research. The central question ceases to be "How can the analyst methodically partition participants' activities into demarcated phases that relate to each other?", and becomes instead: "How do participants understand their activities relative to such matters as 'setting a task', 'following a task', and 'evaluating a task' in whatever practical circumstances locally prevail?”

This study is thus in the line with ethnomethodological studies of work (e.g., Garfinkel, 1986; Button, 1993; Hester and Francis, 2000a) that aim to exhibit professional work as practical accomplishments. Although there have been some studies of classroom 'work', in particular the edited collection Doing Teaching: The Practical Management of

\footnotetext{
${ }^{1}$ See Shapiro (1996) for another comparison of 'task analysis' with 'ethnographic studies' that anticipates some of the arguments developed here.
}

Greiffenhagen, C. (2008). Unpacking tasks: the fusion of new technology with instructional work. Computer Supported Cooperative Work (CSCW) 17 (1), 35-62. 
Classrooms (Payne and Cuff, 1982), the work of James Heap (e.g., 1988, 1989a,b, 1992) and Douglas Macbeth (e.g., 1990, 1991, 1992, 1994, 2000; and Lynch and Macbeth, 1998), by and large the mundane and practical aspects of delivering and receiving instruction in schools per se have been under-researched. This is especially the case with respect to studies of educational technology, which have arguably been framed more in relation to controversies in educational theory and over policy objectives for schooling rather than prioritising the capture of the experience of teachers and pupils who are faced with the mundane and practical affairs of worldly school settings.

Although there is obviously some sense in which teachers are trying to achieve policy and educational objectives, these will have to be achieved as practical matters:

The fact of the matter is that whatever else may happen in schools, whatever far-reaching or revolutionary educational issues may be exhibited or addressed there, the routine, mundane practical activities are fundamental. For teachers and pupils in schools the mundane is inescapable; whatever else may be going on, whatever else may be consequential for wider educational matters, the mundane makes up most of what goes on day by day. (Payne and Cuff, 1982, p. 3)

Ethnomethodological studies of work in this context thus put at the centre of inquiry how members of a classroom determine what counts as successful or unsuccessful instances of learning, how they understand and test for the efficacy of their learning-generating practices, and how they identify outcomes they did not bargain for. In what follows, I will try to show how an ethnographic sensibility, one which grapples with members' sense of 
their phenomenal world, can be allied to close interactional analysis in order to arrive at material that is relevant to interdisciplinary understanding of the role of a technology.

This paper thus also relates to some recent discussions concerning the role of observational studies for design (see, in particular, Dourish, 2006; Randall et al., forthcoming). These discussions have sought to explore the relationship between ethnography and design in more nuanced ways than we have hitherto seen. Historically, much of the debate has surrounded either competing theoretical positions (as with arguments concerning the relative merits of, for instance, distributed cognition and activity theory in CSCW and CSCL) or methodological disputes concerning the role of video, the structure of ethnographic data, and so on (see Dourish and Button, 1998, for a critical review of some of these positions).

In this paper, I want to argue for a methodological eclecticism, drawing on the rigours of conversation analysis (Sacks, 1992) and interaction analysis (Jordan and Henderson, 1995), as well as ethnomethodological studies of work ${ }^{2}$. The argument is not about the relative merits of these commitments in respect of their disciplinary auspices, viz. sociology, but how we are to learn from them for interdisciplinary purposes ${ }^{3}$. For

\footnotetext{
${ }^{2}$ Space precludes a detailed analysis of some of the differences entailed here, but see Lynch (1993), Hester and Francis (2000b), and Randall et al. (2001).

${ }^{3}$ Other authors have, in outline, rehearsed the need for both 'ethnography' and 'interaction analysis' together (see Jordan and Henderson, 1995; Blomberg and Trigg, 2000). They seldom, however, spell out what work it is that the ethnography does.
}

Greiffenhagen, C. (2008). Unpacking tasks: the fusion of new technology with instructional work. Computer Supported Cooperative Work (CSCW) 17 (1), 35-62. 
example, the interest in Computer Mediated Communication (CMC), and in particular the concern for replicating aspects of face-to-face interaction which we have seen in CSCW (cf. Schmidt, 2002), has been accompanied by an analytic concern for such matters as turn-taking, deictic reference, pause, and delay, which in turn recommended approaches inspired by conversation and interaction analysis (e.g., Ruhleder and Jordan, 1999; Koschmann and LeBaron, 2003; Heath et al., 2002). In other words, the focus or topic of the project suggested an analytic approach.

In my case, the phenomenon includes the purposes ascribed to the technology in view, the construal of what it is to participate in a 'lesson', and their mutual constitution in and through the activities observed. The data is used to throw some light on the way in which interdisciplinary purposes, inevitably, effects at least to some degree on the kinds of analytic work the ethnographer might choose to do.

\section{The study}

The analysis is predominantly based on a three-month observational study (January-April 2001) of how a prototype of a new storyboarding tool was used in two school classrooms. The lessons observed were a preparation for the Shakespeare element of their Key Stage 3 National Tests in English (the SATs). During the time of the study pupils spent the majority of their English lessons studying Macbeth through a variety of activities (such as reading the play aloud, listening to audio-recordings, acting out particular scenes, watching the play both on video and at the theatre, etc). Having thus studied Macbeth for some weeks, working with the storyboarding tool became an additional activity for this 
class. In addition to observing and recording the lessons, we carried out several interviews with teachers and students.

In order to understand the rationale behind the storyboarding tool, interviews with key participants in the development process were carried out and key documents from the design process were collected. The software that was used in the lessons under investigation was one of the outcomes of the 'Oxford-Intel Education Initiative', a project that was started by Intel and that involved the Computing Laboratory and Department of Educational Studies at Oxford, as well as several small commercial companies that were developing new technologies. It was a collaboration between educationalists, computer scientists, academics, and software developers. Interviews were conducted with all of parties.

\section{The design of the software}

With respect to any new piece of technology it is always pertinent to ask what the technology was designed for, i.e., about the envisaged purpose or aim. For any sufficiently complex technology (such as the tool under discussion) no one answer to that question will be available, which does not mean that it is not possible to specify some aims and objectives.

The prototype of kar2ouche (software for storyboarding) used in classrooms was the outcome of a collaboration between several University departments (computer science; educational studies; English) and a number of start-up companies. Storyboarding software was not, in fact, the original goal, but became central at the point where it became obvious that the original intention was too technologically demanding.

Greiffenhagen, C. (2008). Unpacking tasks: the fusion of new technology with instructional work. Computer Supported Cooperative Work (CSCW) 17 (1), 35-62. 
Storyboarding is a well-known technique for ‘classroom Shakespeare’ (cf., Gibson, 1998, p.210). The new idea was to computerise this traditional technique in order to simplify the construction of frames thereby making it more enjoyable for pupils. The educationalist described the requirements for the software (in a document dated 18/4/1999) in the following terms:

\section{storyboarding facility}

This would consist of roughly three different related windows: the first would be able to combine images drawn from an image-bank related to the play, of characters with a range of expressions etc. who could be placed in different combinations on different backgrounds; the second would contain short extracts from the text \& act/scene numbers; the third could be used by students to write their own memos/notes about different aspects of the plot \& characters.

Students would thus be able to summarise the story of different scenes/acts, and build up an outline of key moments from the whole play - the chief aim of this element of the software would be, therefore, to help students build their own vivid overview of the play as a whole, but more in terms of plot and characters than in terms of close textual study.

The design brief clearly reflects that the educationalist was not just designing 'a technology', but was designing a technology with general educational objectives and concrete activities in mind. Let me mention just three important features: 
(1) The importance of choices. The software should provide pupils with a variety of resources to tell a story. In other words, the software is envisaged as part of 'creative' or 'active' learning, where the goal is to get students involved.

(2) The emphasis on key scenes. The storyboard is seen as a tool for visualising the play as a series of "key moments" (where what constitutes such a key moment is part of the pre-given cultural appreciation of a play).

(3) The possibility for writing. The educationist is not just conceiving the storyboarding tool in terms of pictures, but also as a way to get pupils to write ("their own memos/notes about different aspects of the plot \& characters").

In particular the last two points suggest another important aspect of the design rationale. The software was envisaged to be used as part of English lessons. One of the most important aspects of English lessons in Year 9 is the national examination (SATs). The kinds of activities that the educationalist envisaged (the pupil as director, expressing their ideas about the play) were directly related to the kinds of questions asked about a Shakespeare play. In an informal interview, conducted two years after this document had been produced, the educationalist expressed the rationale in the following way:

[...] the two main aims of studying Shakespeare at that stage were, to know the story, so to feel familiar and confident about understanding what's going on in the play, not to see the play as something off-putting but rather as something enjoyable, and to be able to express, informed, opinions. But not academically accurate necessarily, but opinions that were reasonable, that they could justify with reference to the text, but not scholarly exegesis,

Greiffenhagen, C. (2008). Unpacking tasks: the fusion of new technology with instructional work. Computer Supported Cooperative Work (CSCW) 17 (1), 35-62. 
just thinking about the text, as it is, and questions about, you know, "Why do you use this word?" "What is that character feeling now?" "If you were the producer, how would you make the character act?” (Interview, 8/11/2001)

The aim of the software was to facilitate creative and active learning, and close engagement with the text. It was based on the view that thirteen to fourteen year old children would often have difficulty understanding Shakespeare, as well as finding Shakespeare generally unappealing. The design was further based on the realisation that it would have to, in some way or other, contribute to a preparation for the SATs.

As a consequence, educational theories about the engagement and motivation in school children are designed 'into' the technology - as are views about the ways in which using computers provide for interesting work. The software was seen as a means of making demands on the pupils, construed in notions about their age, ability, and so on. The demands made in use of the software are of the sort that should make pupils think about how to do something they have not done before, provide them with ways of making a choice from doing those things, and give them a 'decision problem' of choosing out of several possible ways of doing something. The software is demanding also in the sense that pupils will have to pay quite refined attention to the features of both the text and the technology's resources.

For the teacher the aim will be to ensure that these demands are feasible demands. Consequently, any teacher who wants to use this software as part of their lessons on Shakespeare will have to decide, inter alia, what exactly the pupils should do with it, 
what he or she expects the pupils to get out of using the it, for how many lessons it should be used, and so on.

\section{The use of the software}

The analysis of how the software was used follows the sequence of the classroom lessons. The analysis will focus on one of the two classes, where the teacher used the software as part of seven computer lessons over a period of five weeks (i.e., with several noncomputer lessons in between). The pupils worked either alone or in pairs.

The first lesson was spent almost entirely with the teacher introducing the software and the task (what pupils should do with the software). The teacher would explain a feature of the software at the front of the class, and then give students a few minutes to experiment on their own, before introducing the next feature of the software. A quick reformulation of the task was given at the beginning of the second lesson. After that, the majority of the time was given over to students to work on their own, while the teacher would 'make rounds' and review the progress of individual pupils, as well as make occasional whole-class announcements. As a consequence, the analysis starts by focussing on the teacher's whole-class announcements, before looking at what the pupils subsequently did.

\section{Setting the task}

Transcript 1 displays how the teacher introduced the software in the first computer lesson.

\section{Transcript 1 [Feb 16; first computer lesson]}

$01 \mathrm{~T}$ : $\quad \mathrm{y}^{\prime}$ remember how I was showing you yesterday (.) I showed you

02 (.) I showed you three different versions of (.) Macbeth (3.0)

03 did I not show you that?

Greiffenhagen, C. (2008). Unpacking tasks: the fusion of new technology with instructional work. Computer Supported Cooperative Work (CSCW) 17 (1), 35-62. 
04 Pn: yeah

$05 \mathrm{~T}$ : what we gonna do $(1.0)$ is we gonna think about (.) how (.) if

06 we were (1.0) directors (.) if you were directors (1.0) how

would you (5.0) >just take your hands away from the mouse, just leave everything (.) for the minute (.) okay? (.) take your hands off the mouse $(3.0)$ how would you $(1.0)$ have $(1.0)$ act two, scene two (.) >how would you have it played? (1.0) how would you play it out? when Macbeth comes back from the murder (.) how would you have him behave? (3.0) alright? (.) what would you have him do? (.) or we could have act two, scene one (1.0) when they're planning the murder (.) how would they, how would they behave? (.) how would Macbeth and Lady Macbeth behave? (.) what poses etcetera will they strike? (.) okay?

[...]

before a film is made (2.0) you always get a storyboard (.) ((aside to a pupil)) you don't need the text, the text's already on there (.) you always get a storyboard (1.0) it's a series (.) of pictures (.) that goes to make up the final film (1.0) what we've got here (.) is some whizzy new software $[\ldots]$ what this allows you to do $(1.0)$ is to make your own storyboards (.) okay?

In lines $1-3$, the teacher starts by telling the pupils that what they will be doing in this lesson is related to what they have done previously (namely watching three different versions of Macbeth). Thus right from the start, the teacher is making clear to the pupils that this activity is part of some larger, overall activity (namely to learn about Macbeth as a preparation for the SATs). In other words, both teachers and pupils are aware that the current lesson is not 'free-standing', but part of a whole series of lessons (cf., Payne, 1979, pp. 86-88; Payne and Hustler, 1980, p.56) that will cover a particular theme, such as learning about Shakespeare's Macbeth. That project will be approached through several activities or tasks, including watching different versions of the play (previous lesson) and constructing a storyboarding (this and subsequent lessons) ${ }^{4}$.

\footnotetext{
${ }^{4}$ Elaborated reminders are not always necessary. The next lesson is introduced with a simple announcement:
}

Greiffenhagen, C. (2008). Unpacking tasks: the fusion of new technology with instructional work. Computer Supported Cooperative Work (CSCW) 17 (1), 35-62. 
Having reminded the pupils about the previous lesson, the teacher starts to tell pupils what they will be doing in this (and possibly subsequent lessons): "what we gonna do" (line 5). The teacher announces that in this and the following lessons the pupils will produce a storyboard of Macbeth that will indicate how they would have the play acted out if they were directors.

It is a common feature of classroom lessons that at the beginning of each lesson the teacher will announce what the lesson will be about (the topic) and what the pupils will have to do during the lesson (the task):

A characteristic of many lessons is that they contain prefaces in which the teacher explicitly formulates the topic and the activity that is to follow. (Anderson, 1979, p.47) ${ }^{5}$

Note that the teacher has to make sure that the pupils will listen to her instructions, before they begin to use the software. The teacher says: "just take your hands away from the mouse, just leave everything” (lines 7-8). This points to the issue of classroom

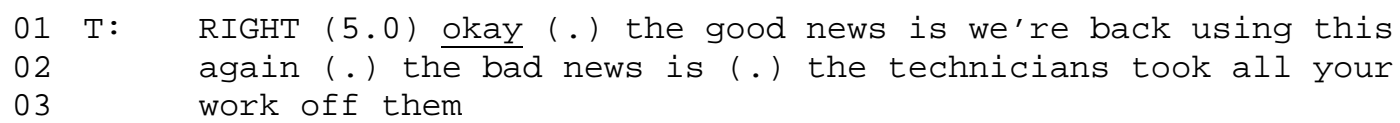

Here the teacher can rely on the fact that coming to the computer suite (rather than staying in their normal classroom) pupils will remember that they have been working with the software to produce a storyboard. One may also note that such 'whole-class announcements' are often prefaced through special markers, in particular "right”, through which the group of pupils is established as a cohort (cf., Payne, 1976).

${ }^{5}$ On topics in classroom lessons, see also Payne and Hustler (1980), McHoul and Watson (1984), Heyman (1986), and Heap (1988).

Greiffenhagen, C. (2008). Unpacking tasks: the fusion of new technology with instructional work. Computer Supported Cooperative Work (CSCW) 17 (1), 35-62. 
management. The teacher is actively separating the lesson into 'instruction' and 'doing' phases, making sure that the pupils first listen to the teacher's instructions, before enacting them with the computer. This feature of these kinds of activities has also been observed by Hemmings et al. (2000, p.237) in the context of experiments in museums:

the teacher determines the appropriate time to begin experimentation and actively prevents experimentation until some attention has been given to the instructional text and description of condition has been noted.

In this lesson, the teacher explains to the class that she wants them to imagine that they were a director and would have to direct a particular scene from the play: "if you were directors [...] how would you (1.0) have act two, scene two (.) > how would you have it played?” (lines 6-10). The teacher illustrates this general question by giving an example of a scene, namely the one between Macbeth and Lady Macbeth, after Macbeth returns from having murdered King Duncan (Act Two, Scene Two).

The teacher thus makes clear that the focus will be on a particular scene from the play. Furthermore, the pupils will be aware that this will not be any scene from the play: each year the SATs will focus on two particular scenes from a play (which in 2001 were Act Two, Scenes One \& Two and Act Four, Scene One), and this is one of them. In addition, the teacher's instruction exhibits that the new activity is related to what pupils have already learned about the play in previous lessons. Thus the teacher's example in lines $11-16$ is not telling them what is happening in that scene. Rather, the teacher is assuming that they know the content of the scene, and the question becomes: how is that content to be visualised?

Greiffenhagen, C. (2008). Unpacking tasks: the fusion of new technology with instructional work. Computer Supported Cooperative Work (CSCW) 17 (1), 35-62. 
In the teacher's introduction to storyboarding, she motivates what the pupils will have to do through the use of the membership category 'director' (line 6). That is to say, the instruction is categorially instructed (cf., Sacks, 1972). The teacher takes advantage of the existing common-sense cultural knowledge of pupils who are supposed know (in a more or less definite sense) what directors do. The category 'director' has certain category-bound activities (e.g., making decisions about how particular scenes should be played out) as well as certain responsibilities (e.g., being able to justify these decisions).

By using a particular category device in setting a task, teachers can set up a set of rights and responsibilities rooted in common categorially-attributed knowledge (cf., Sharrock, 1974, p.52). That is to say, once a categorial instruction has been provided, what pupils subsequently do can be seen in terms of that category. The category device can be used as a sense-making device: Is what the pupils are doing appropriate to that category or not? This is nicely exhibited in the following exchange, which occurred toward the end of the first computer lesson. The teacher is 'making rounds' when a pupil asks her a question:

\section{Transcript 2 [Feb 16; first computer lesson]}

$01 \mathrm{P}: \quad$ is Banquo smaller than Macbeth?

02 T: it's up to you really, you're directing it

The pupil seems to be asking a perfectly sensible question: Should she be making Banquo smaller than Macbeth? However, the teacher refrains from answering that question and instead hands the question back to the pupil. Handing back the question to the pupils indicates that there is no single 'correct' answer and requires the pupil to make a decision herself. The handing back is done on the grounds that the activity that the pupil is currently engaged in ('directing') precludes asking for help for this sort of problem. Since it is directors who direct, the teacher responds to the pupil's question in terms of 
her earlier categorial instruction (i.e., this is the kind of the question that pupils qua director should decide for themselves). It is through the use of 'pro-active' categories such as 'director' that what educationalists call 'ownership' is achieved. That is to say, there are certain categories of people who are known, commonly, to make decisions (e.g., directors or managers) and others who do not (e.g., servants). Entitlements to perform certain activities are tied to such 'pro-active' categories. Hence, if the teacher wants pupils to 'own' their work, she will choose such a category.

To conclude the analysis of Transcript 1, let us look at lines 19-26. Here the teacher defines what a storyboard is, namely "a series (.) of pictures (.) that goes to make up the final film". This leads to a characterisation of the software as "some whizzy new software”, which "allows you [...] to make your own storyboards”. The teacher thus not only tells the pupils what a storyboard is, but that the pupils will be producing storyboards using the technology.

\section{Technology and task}

Having told the pupils what the topic and task of the current lesson is (to produce a storyboard using the software), the teacher goes on to talk about the technology. The following excerpt (Transcript 3) follows on directly from the setting of the task that we saw in Transcript 1.

\section{Transcript 3 [Feb 16; first computer lesson]}

$01 \mathrm{~T}$ : let's imagine that we are working on the bit where Banquo 02 (1.0) goes and-(.) >where Macbeth visits Banquo and Banquo is

03 out with his son (1.0) yeah? the very start of act two, scene

04 one (.) let's pretend we are working on that, okay? (.) what

05 you need for that scene? imagine that you are a director, 06 you've got a pile of sheet of paper in front of you, whatcha 07 need for that scene? what are you gonna need? who you gonna 


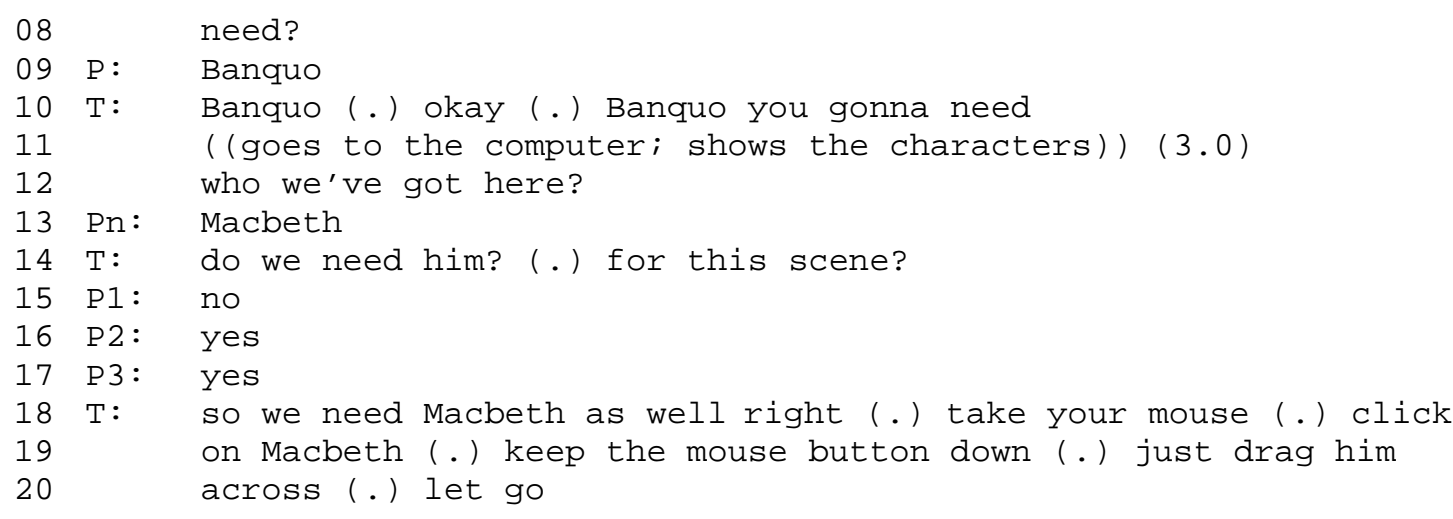

Having told the class that they are going to produce a storyboard, which is "a series (.) of pictures”, the teacher now explains how they are going to construct the storyboard using the software. This is done by "imagining" (line 1) that they are working on a particular scene. The teacher takes as an example Act Two, Scene One, when Banquo is outside with his son and Macbeth visits them (lines 1-4).

She asks the pupils: "what you need for that scene" (line 5), and reminds them that they are supposed to be in the position of a "director" (cf., 'categorial instruction' above). In other words, faced with "a pile of sheet of paper in front of you" (line 6), what kind of materials would the pupils need in order to construct a storyboard?

The teacher's first few utterances (lines 1-5) make sure that the question "watcha need for that scene?” is not heard as an 'open' question, but as a question that delimits what would count as a possible answer. Any potential answer would have to be hearably related to that particular scene (knowledge of the story of the play) and to the kind of things that directors are concerned with, e.g., characters, set design, props, lighting, etc. (knowledge of plays or movies). 
In line 7, the teacher further specifies her question: “who you gonna need?” This question gets a prompt answer ("Banquo") from one of the pupils. The quickness of the response exhibits that, firstly, pupils are actively listening to the teacher, and, secondly, that the teacher's question is now so specific that it is easy for pupils to produce a candidate answer. That is to say, these kinds of questions are part of a well-known format in school classrooms, often called 'questions with known answers' (cf., Macbeth, 2003), where teachers ask question in such a way, that pupils' answer will form the material for teacher's subsequent questions or activities.

Here, the teacher ratifies the pupil's answer by using it as a topic initiator to start talking about the storyboarding software (line 11). In other words, the teacher uses the answer as an opening to go through the features in the software. The teacher goes to her computer (which is also projected onto the whiteboard at the front of the class) and selects 'characters' (see the interface in the appendix). On selecting characters, the software displays Macbeth in the box on the right of the screen ${ }^{6}$. Thus the teacher's next question, “who we’ve got here” (line 12), is answered by many pupils with “Macbeth” (line 13).

The teacher now asks whether Macbeth is needed for the scene that they are in the process of visualising: “do we need him? (.) for this scene?” (line 14). This question exhibits the teacher's attempt to preserve the pupil's original answer ("Banquo") that touched-off the introduction of 'characters'. That is to say, the teacher introduced the 'character' feature in response to the pupil's suggestion that they need Banquo in this

\footnotetext{
${ }^{6}$ Users can scroll through the available characters by pressing the 'up' and 'down' arrows below that box.
}

Greiffenhagen, C. (2008). Unpacking tasks: the fusion of new technology with instructional work. Computer Supported Cooperative Work (CSCW) 17 (1), 35-62. 
scene. However, the first character that is displayed is not Banquo, but Macbeth. The teacher is thus faced with the choice: Does she spend time browsing through the bank of characters until she finds Banquo - or does she use Macbeth to get things moving on?

The purpose of the current activity is not just to construct a storyboard of a particular scene, but also to instruct the pupils in the use of the software, e.g., how to insert a character into the frame. For that purpose it does not matter whether the to-be-inserted character is Macbeth or Banquo. However, although the main purpose is to instruct pupils in the use of the software, the teacher does not lose sight of the fact that the goal is to construct a picture of a particular scene. So in line 14 she asks: "do we need him? [i.e., Macbeth] (.) for this scene?” After several pupils answer positively (lines 16-17), the teacher concludes that they need Macbeth as well as Banquo (line 18) and goes on to instruct the pupils how to insert Macbeth into the frame.

What is noteworthy about this fragment is the fact that the teacher does not only instruct the pupils how to use the technology, but she instructs the pupils in how to use the technology for the purpose of constructing a storyboard of a particular scene. The features of the software (here: characters) are introduced in relation to the overall aim of producing a visualisation of a particular scene. This orientation is preserved. Thus when the teacher selects 'characters' on the software, and the first character that appears is Macbeth, she does not just use Macbeth as an example of how to insert a character. She first makes sure that Macbeth is relevant for this particular scene, and then demonstrates how to insert him.

Greiffenhagen, C. (2008). Unpacking tasks: the fusion of new technology with instructional work. Computer Supported Cooperative Work (CSCW) 17 (1), 35-62. 
In sum, the teacher is not explaining technological features 'in general' ("you can do the following things...”), but in relation to an exemplar, i.e., through an instance of use. The instruction in how to use the technology and the instruction of the task (what to use the technology for) are intertwined. That is to say, the teacher need not first explain the technical functionalities of the software, and then tell pupils what they do with it. Rather, the teacher may tell the class simultaneously how to use the technology and what they should do with it.

Most features of the software were introduced by first asking about what was needed for the storyboard, and then showing how to do this with the technology. Thus having inserted Macbeth and Banquo, the teacher asks what the characters need to do in a scene, before demonstrating how different 'poses' can be selected for a character. 'Backgrounds' and 'props' are introduced in a similar way (the teacher thus follows the layout of the interface - characters, backgrounds, props - in her introduction of software features). Occasionally, however, the teacher first introduces a feature of the technology, before explaining how that feature can be used for the construction of the storyboard. The following fragment (Transcript 4) occurs a few minutes after the previous one (Transcript $3)$.

\section{Transcript 4 [Feb 16; first computer lesson]}

$01 \mathrm{~T}$ : you can do this (.) ahhh:: : (.) shush (3.0) with your though-

02 (.) >if you see (.) at the bottom of the (.) row of 03 characters, backgrounds, props, and then at the bottom there, 04 you've got text bubble (1.0) click to the (2.0) right hand 05 side of that (.) you've got thought bubble $06 \quad[\ldots]$

07 what you can do here (.) is you can type or move in (.) bits 08 of text into the speech bubble to show what they are saying $09 \quad(1.0)$ and then in the thought bubble show what they are 10 thinking (1.0) remember when Banquo meets Macbeth (3.0) and 11 they talk about (1.0) uhm (1.0) Banquo says "Oh, I've been 


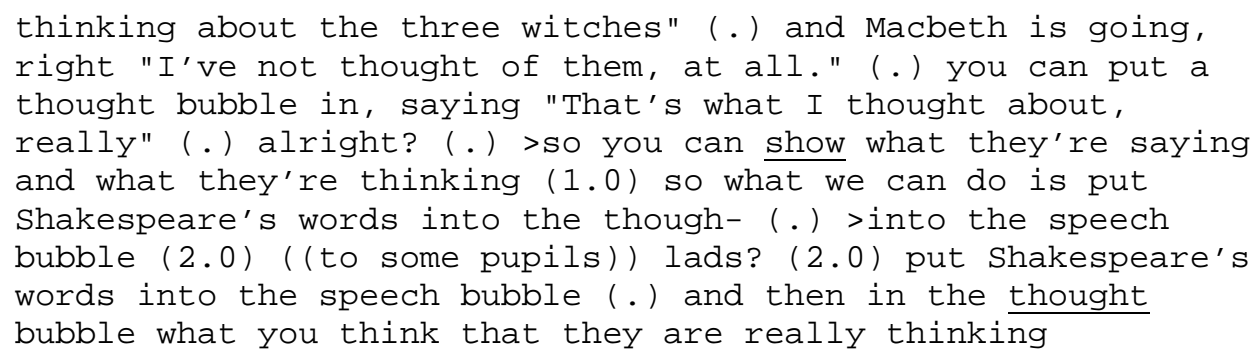

The teacher points to additional features of the technology: 'text' and 'thought bubbles' (lines 4-5). Having instructed the class how to insert speech and thought bubbles (which is omitted in the transcript), she then goes on to say how the pupils should use speech and thought bubbles, namely to show what the characters are saying and thinking respectively (lines 8-10). This introduces not just a resource but a requirement: the teacher wants the pupils to use speech and thought bubbles to elaborate on the dialogue in the text. Doing that will be a feature of 'good' work. The introduction of thought bubbles is clearly related to the educational goals that the teacher wants to achieve. As noted in the section on the design of the software, one of the requirements of the SATs is for pupils to be able to write about the motivations of characters. The teacher is here using a technological feature (the thought bubbles) to get pupils to think about, and express, their interpretation of the characters' motivations.

The new features are again illustrated through an exemplar. In other words, the teacher explains how the speech and thought bubbles should be used in relation to the example scene (between Macbeth and Banquo and his son). The teacher reminds the pupils that as a reaction to Banquo's comment that he has been thinking about the three witches (line 11), Macbeth says that he has not thought about them, whereas it is pretty clear that “really" he has been thinking about them (lines 13-15). In other words, Macbeth’s verbal 
utterance could be put into the speech bubble, while his inner reflections could be put into the thought bubble.

The educational goals can also be seen in the instruction of how to use the 'caption box' at the bottom of each frame. The following excerpt is from the second computer lesson:

\section{Transcript 5 [Mar 2; second computer lesson]}

$01 \mathrm{~T}$ : then at the bottom in that white (.) see the white space at 02 the bottom? (.) the big white space at the bottom underneath 03 the picture (.) in there (.) type in (2.0) your reasons (.)

04 for choosing (.) that background (1.0) those thoughts (2.0) 05 okay? that backgrund (.) those thoughts (.) what are your ๑6 reasons?

The 'caption box' feature is not only introduced in relation to the construction of a storyboard frame for a particular scene, but can also be heard by the pupils as being related to educational objectives. The aim of the current activity is not just to construct 'pretty pictures', but to help with the understanding of the play - and the caption box is supposed to be used by pupils to exhibit their understanding by writing down their rationale for constructing a frame in the way they did.

The 'thought bubble' and 'caption box features are employed by the teacher in a way that resembles the 'third window' in the original design brief of the educationalist, which “could be used by students to write their own memos/notes about different aspects of the plot \& characters”. It is these two features that are most directly linked to the overall goal of the current activity (and related activities), namely the preparation for SATs.

In sum, the introduction of the software and the introduction of the task (what the pupils should use the software for) are interwoven in various ways. What the software can do and what the pupils should do with it are introduced simultaneously - and each elaborates 
the other. There are good reasons for this. Firstly, it seems more economical (i.e., separating the introduction to the technology from what they should do with it would take more class time). Secondly, it displays that the teacher is not interested in the technology per se, but what pupils can do with the technology. In other words, the topic of this lesson is very clearly not the learning of technology, but of a play by Shakespeare (i.e., it is not an IT lesson, but an English lesson).

\section{Structuring the task}

As already mentioned, the teacher spent the first lesson instructing the class in how to use the technology as well as telling them what to do with it. At the beginning of the second lesson involving computers, the teacher finishes her quick overview of the main features in the following way (Transcript 6):

\section{Transcript 6 [Mar 2; second computer lesson]}

$01 \mathrm{~T}$ : start constructing your scenes (1.0) this is the work you're 02 gonna save and work on for the next week (2.0) so by this time 03 next week (1.0) we're gonna have a fair interpretation of this 04 scene from each of you (1.0) any questions? (1.0) anybody not 05 know what I want them to do? (1.0) so you're gonna put in your 06 characters (.) put in your speech-choose a bit of speech from 07 the text and put in the thought bubbles (.) and underneath say 08 why you made the choices that you made alright?

This summary marks the beginning of a new phase. Although pupils have already used the technology, this was done in order to learn about the technology. The teacher now indicates that this 'practice' period is over and instead pupils are supposed to produce 'work'. The teacher indicates that the pupils should now have enough resources to complete the task (“a fair interpretation of this scene”). Finally, the teacher points out that the task is not to be completed by the end of the current lesson, but that pupils have until next week to complete the task. 
In lines 5-8, the teacher in effect suggests a four-step sequence: picture construction, speech bubble, thought bubble, and caption box. The outline of the task thus provides pupils with a resource for structuring subsequent activities. The construction of a frame is broken down into four steps, which can be done one after the other. This four-step sequence, while of course not an 'unforgivingly strict sequence', was nonetheless followed by pupils throughout these lessons. In other words, pupils oriented towards this sequence.

An example of this can be found in the following excerpt (Transcript 7), where two pupils are working together. One of the pupils is typing into the thought bubble (the third step). When he has finished, the other pupils tells him that the next thing to do is to work on the caption box (the fourth step).

\section{Transcript 7 [Mar 12; sixth computer lesson]}

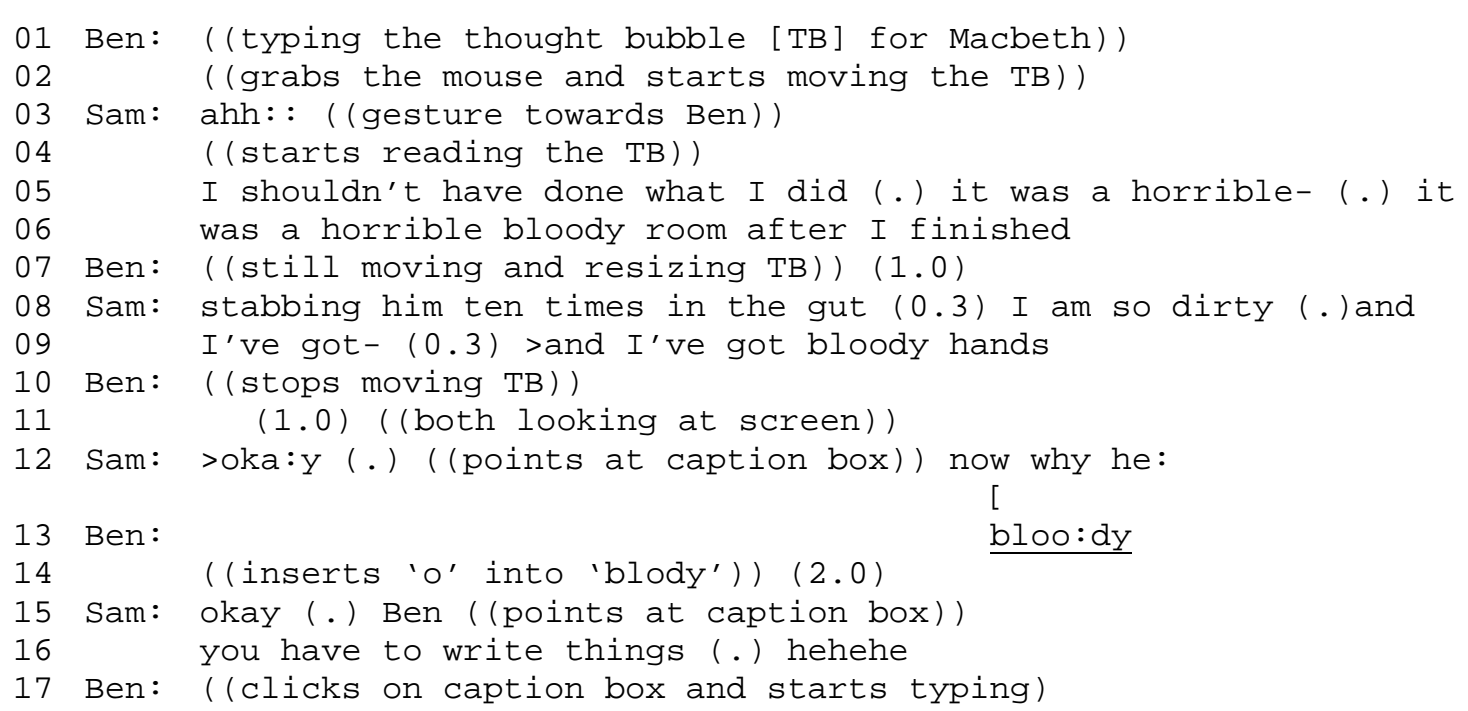

In this fragment, Ben has access to the keyboard and is writing in the thought bubble for Macbeth. Having finished typing, he moves and resizes the thought bubble, while Sam is trying to read what Ben has written. Once Ben has finished, both pupils look at the screen 
(line 11), before Sam remarks: "okay (.) now why he”, pointing at the caption box, indicating that the next step that Ben should be doing is to write in the caption box. After Ben has corrected a spelling mistake, Sam repeats his remark: “okay (.) Ben (.) you have to write things"7. In response, Ben gets hold of the keyboard and begins typing in the caption box. That is to say, Sam is orienting to the aforementioned four-step sequence: after thought bubbles, comes the caption box.

With respect to the teacher's whole-class instruction of the software and task, we might say that the teacher has to provide pupils with enough resources so that pupils can get started. That is to say, once the teacher has finished with her introduction and asks pupils to "start putting together your own little storyboards", every pupil in the room should be able to begin. A teacher would want to avoid a situation where she asks the class to get going and many pupils rather than starting to work would not know what to do. One of the ways in which the teacher can help pupils to get started is by sequencing the task, i.e., by breaking it down into a number of steps. Sequencing a task has the advantage of simplifying it, since the serial structure helps pupils to figure out what to do next. This seems to be a familiar phenomenon of everyday life: when faced with a task which appears too 'big' or 'complicated' to solve, one way to tackle it is by imposing a sequential structure onto it.

\footnotetext{
${ }^{7}$ One might note that the "okay" (in lines 12 and 16) works as a kind of 'formal marker' (Turner, 1972, p.369) that indicates the proposed start of the next step/phase.
}

Greiffenhagen, C. (2008). Unpacking tasks: the fusion of new technology with instructional work. Computer Supported Cooperative Work (CSCW) 17 (1), 35-62. 


\section{Reviewing the task}

Of course, when setting the task (when telling pupils what they should do), the teacher does not need to tell the pupils 'everything'. It is not necessarily a problem if pupils later get 'stuck' or make 'mistakes'. Once the task has been given the teacher does not sit back at the front of the class, waiting for the pupils to 'do' what she has told them. Rather, once the teacher has finished her introduction, she goes around the room in order to look at what pupils are doing and have done so far. Teachers 'making rounds' is a familiar feature of pair- or group-work in schools (Mehan, 1989, p.10).

Very frequently, the teacher would approach a pair of pupils, look at what they have done, and simply ratify or 'okay' it:

\section{Transcript 8 [Mar 12; sixth computer lesson]}

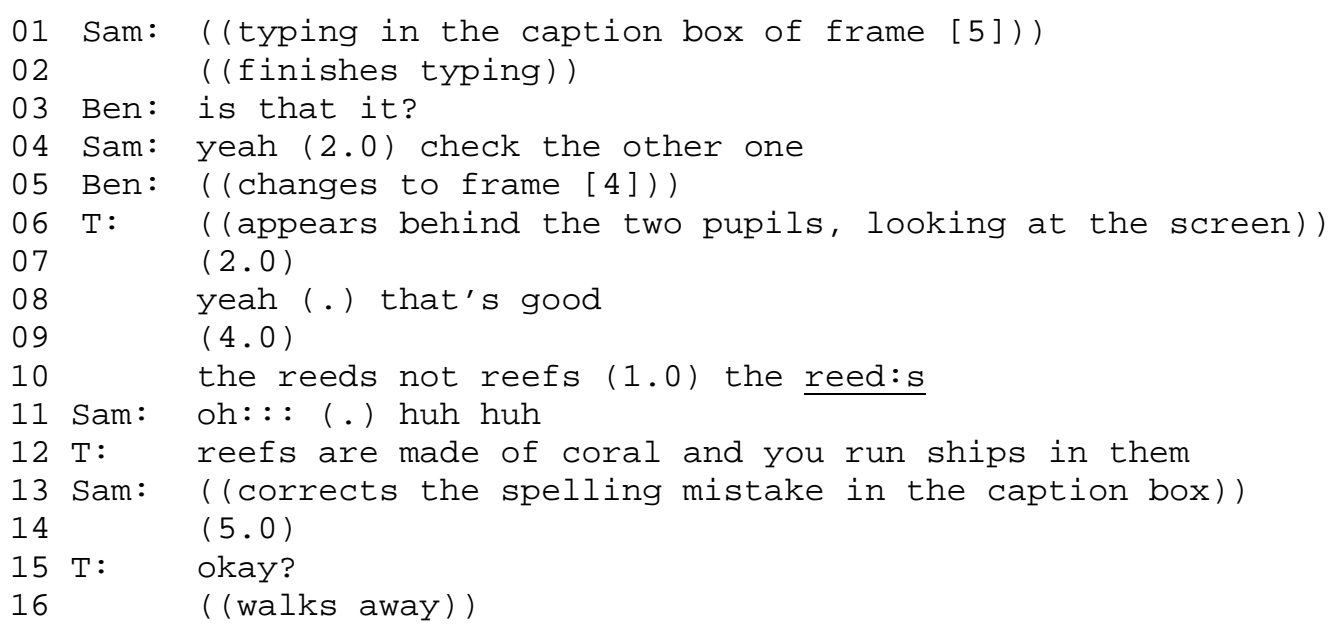

The teacher approaches behind a pair of pupils (line 6), briefly looks at the screen, and then remarks: "yeah (.) that's good” (line 8). After a short pause, the teacher points out a spelling mistake in the caption box of the fourth frame and then moves on. 
This short 'review' episode exhibits how the teacher can ratify pupils' completion of the task. It is through such 'okaying' that the teacher can let pupils know that their understanding of the task aligns with hers and that they are going in the right direction. Note that the correction of the spelling mistake again points to the wider context in which these activities take place. Although the current focus is on the visualisation of a scene from the play, it is still an English lesson. Furthermore, as pupils will be aware of, they will be marked on spelling and grammar in their SATs and this account for why the teacher feels it necessary to point out the spelling mistake - although the frame is otherwise "good"

In these lessons, the teacher was predominantly satisfied with what pupils did. However, sometimes the teacher had to remind pupils about an aspect of the task that they had not fulfilled. The following excerpt is an interchange between the teacher and a pupil working on her own.

\section{Transcript 9 [Mar 2; second computer lesson]}

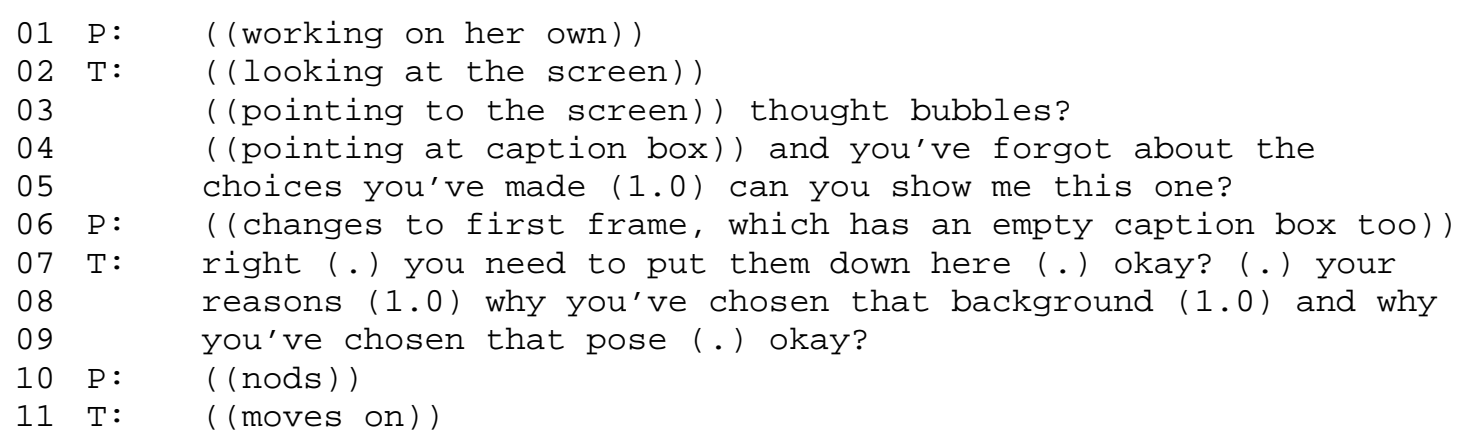

\footnotetext{
${ }^{8}$ The other teacher in our study once reminded the class: "In your SATs, you will lose marks if you are not spelling words correctly.”
}

Greiffenhagen, C. (2008). Unpacking tasks: the fusion of new technology with instructional work. Computer Supported Cooperative Work (CSCW) 17 (1), 35-62. 
While reviewing the work of the pupil, the teacher points out the lack of thought bubbles and the empty caption box in the current frame (lines 2-5). The teacher then asks to see the previous frame - presumably in order to check whether it is only this frame that has no text in the caption box, or whether the pupil has failed to complete the caption box of the previous frame. In other words, checking the previous frame gives the teacher the resources to see if the state of the current frame displays a 'problem' or whether the current frame just as - yet - unfinished (and that thought bubbles and writing in the caption box will be done next). The teacher finds the latter to be the case, prompting a reminder for the pupil to write into the caption box her "reasons" (lines 7-9).

The work that the teacher reviews points to an incomplete task. The teacher not only points this out to the pupil, but also provides instructions as to how to complete the task (namely by writing in the caption box about her 'choices'). This part of the task, the writing of reasons in the caption box for why they had constructed the picture in a particular way, was the one aspect of the task that the teacher frequently had to remind pupils about. In a post-lesson interview the teacher remarked to me that the pupils are "so taken with the pictures which is great (.) but they're not getting their reasons in”. The teacher also made frequent whole-class announcements about this, e.g.:

\section{Transcript 10 [Mar 6; fourth computer lesson]}

01 whilst this is a great exercise (.) your director's board

02 (.) it is (.) I need to know why you're making those choices

03 (.) 'cos that's what's going to get you through your SATs (.)

04 you're not going to have kar2ouche in your SATs (.)

05 unfortunately >it would be wonderful if you could

Note that the teacher explains the importance of the writing in the thought bubbles and caption box with reference to the wider context (preparing pupils for their SATs). What is

Greiffenhagen, C. (2008). Unpacking tasks: the fusion of new technology with instructional work. Computer Supported Cooperative Work (CSCW) 17 (1), 35-62. 
educationally noteworthy about the current task is tied to what the pupils will eventually have to do in the written exam.

\section{Following the task}

So far tasks have been considered predominantly from the perspective of the teacher. I now want to approach them from the perspective of pupils. Although tasks can be thought of as a set of instructions, for pupils they are more likely puzzles to be solved (within certain parameters). That is to say, since instructions do not include their own application, it is the job of pupils to figure out how to adequately accomplish the task (i.e., they have to figure out what the teacher wants them to do). Here is one example:

\section{Transcript 11 [Mar 2; second computer lesson]}

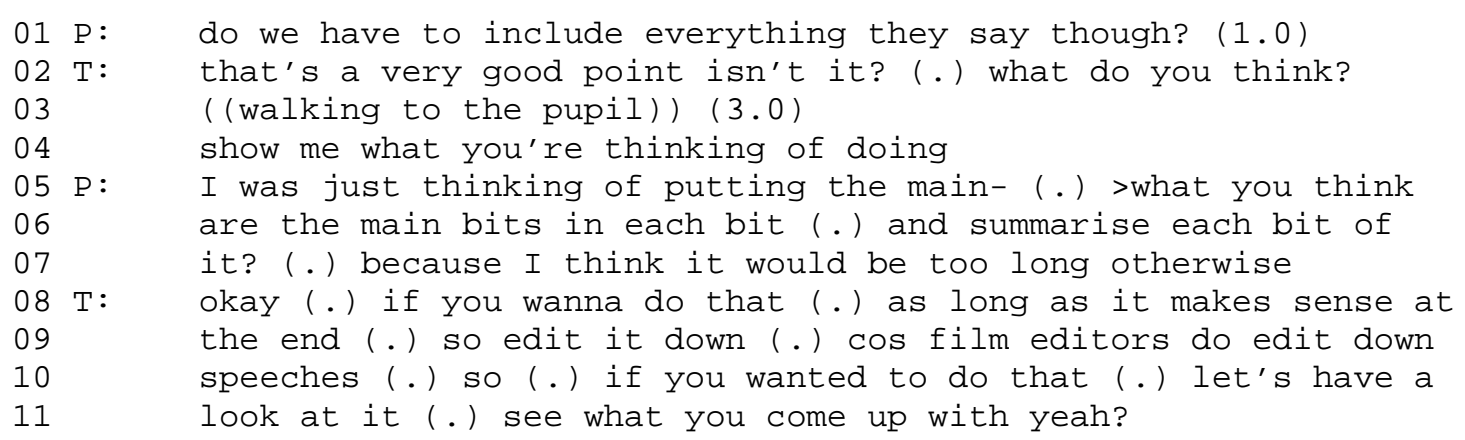

The pupil's question (line 1) displays that she is aware of the teacher's instruction with respect to the speech bubble ("put Shakespeare's words into the speech bubble (.) and then in the thought bubble what you think that they are really thinking”). However, this instruction does not cover the question of whether she can just put "the main bits" (line 5) into the speech bubbles, which would still fall under the auspices of "putting Shakespeare's text into the speech bubble”. 
In this case, the teacher 'okays' the pupil's proposed way of following the task (line 7). The teacher not only accepts the pupil's suggestion, but provides an additional account of why this is acceptable, namely because “film editors do edit down speeches” (lines 8-9). That is to say, the teacher makes sense (for herself and the pupil) of the pupil's suggestion by reference to the earlier categorial instruction (see above): what the pupil is proposing to do is acceptable because it is in accordance with what directors do. Again, the responsibility for the decision is given back to the pupil: "see what you come up with” (line 10).

The next fragment is another example of pupils trying to figure out how to comply with the teacher's formulation of the task. The two pupils have inserted eight speech bubbles into the current frame (see Figure 1).

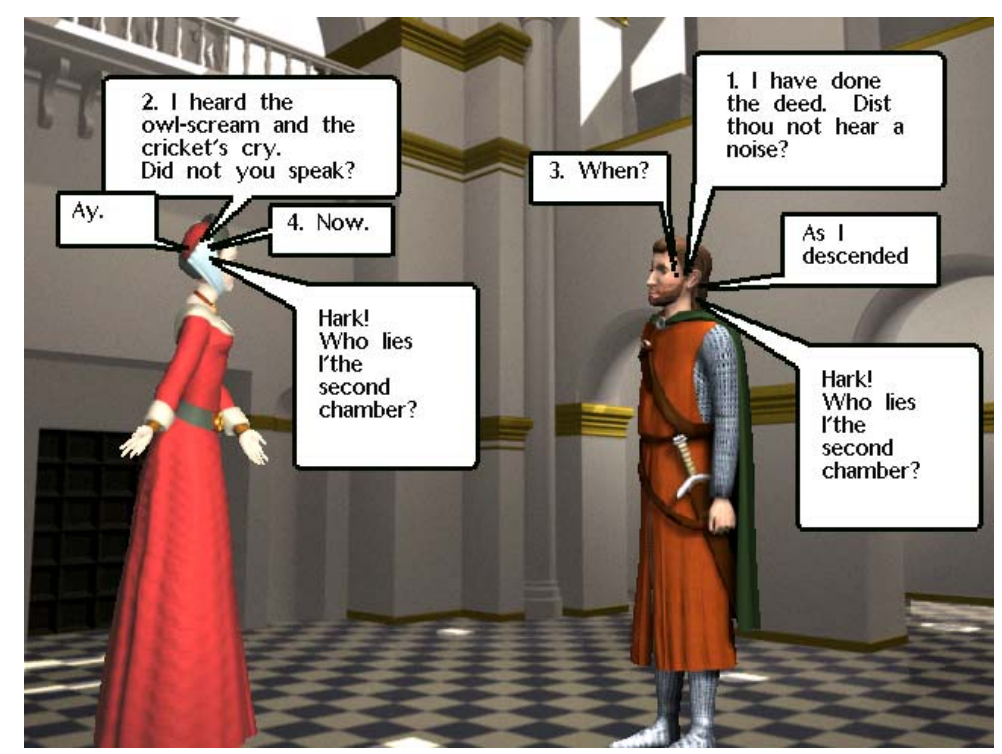

Figure 1: the current frame [reconstructed]

The pupils are in the process of numbering the speech bubbles in order to indicate the order in which they should be read, when the teacher approaches behind them. 


\section{Transcript 12 [Mar 9; fifth computer lesson]}

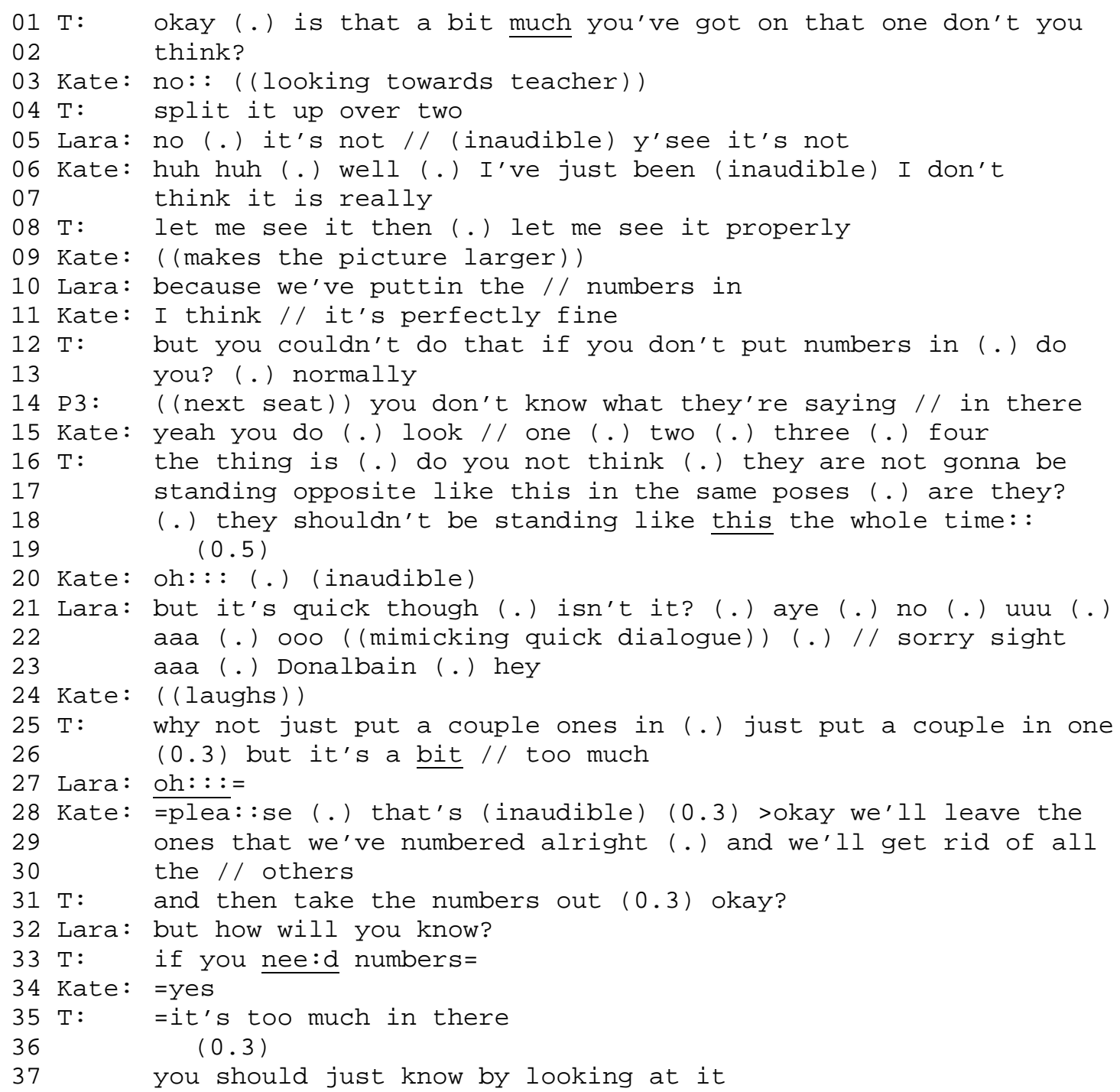

The teacher questions whether there are too many speech bubbles in the current frame (line 1), and suggests that they should split the speech bubbles over two frames (line 4).

The teacher's first utterance, although having the form of a question is hearably also a reproach (cf., Macbeth, 1990) of what the pupils have done in this frame. In the classroom, formulations such as "don't you think that ..." or "might it not be better if ..." are a way soliciting a concession from pupils. However, in this fragment there is a marked reluctance on the part of pupils to concede. The teacher's initial question is 
answered negatively by both pupils (lines 3 and 5). Similarly, the teacher's next suggestion (lines 16-18) is followed by a marked silence (line 19), before one of the pupils argues that their visualisation has the advantage of exhibiting a 'quick' dialogue (lines 21-23), which could be a counter to the teacher's claim that the characters shouldn’t be standing in the same pose during the whole dialogue (since a character could be in the same pose for a quick dialogue).

There is a clear sense in which the pupils are trying to convince the teacher that their current solution is acceptable by pointing out that they have numbered the speech bubbles (line 10) and displayed the quickness of the dialogue (lines 21-23). However, the pupils orient to the fact that their accounts are only candidate solutions, which have to be validated by the teacher. This is particularly visible in line 28, where Kate starts her utterance with "please”, indicating that they are trying to get the teacher's approval. Despite their reluctance, the pupils eventually accept the teacher's suggestion, even the fact that they should remove the numbers (line 31). This points to another feature of tasks: although tasks are achieved by pupils, they are ratified by the teacher. That is to say, it is ultimately up to the teacher to decide whether or not what pupils are doing will count or not count as 'following the task'. There is thus an asymmetry with respect to tasks, since it is only teachers (and not pupils) who can ratify the realisation of a task (cf., McHoul and Watson, 1984, p.301; Heyman, 1986, p.54).

Note again how the teacher provides a rationale for her suggestion to split the current dialogue over two frames. Firstly, the teacher argues that one should be able to discern the order in which to read the speech bubbles simply by looking at the frame (i.e., without the additional feature of numbered speech bubbles). Secondly, as in the previous 
fragment, the teacher argues that in a production of the play the characters "are not gonna be standing opposite like this in the same poses” (lines 16-17).

In sum, the teacher's initial instruction “put Shakespeare’s words into the speech bubble (.) and then in the thought bubble what you think that they are really thinking”, although providing some parameters for pupils, did not provide them with concrete answers, for, how much of Shakespeare's text they should use ('all' the dialogue or just the 'key bits') and how much of Shakespeare's text should they use per frame. These were, for pupils, contingent features of getting through the task.

\section{Discussion}

I have tried to show that there are not, and cannot be, any convenient boxes into which we can place examples of 'purpose' and 'task'. I have discussed some aspects of the purposes of the technology in the eyes of an educator and a teacher. For example, the teacher exhibited an awareness of the need to use a new technology in appropriate ways, which relate to a set of externally imposed criteria in the SATs. These many and different goals can be both stated and exhibited in a number of different contexts (the interview, the observation) by a number of people (the educationalist, the designer, the teacher). In any event, it is also evident that these purposes are made visible in the accomplishment of tasks as they are construed by the parties to them (teachers and pupils).

As we have seen, the teacher spent the first one and a half lessons instructing pupils (while giving them space to practice on their own), before letting them work on a small project for a couple of lessons. In order to make sense of these subsequent activities, it

Greiffenhagen, C. (2008). Unpacking tasks: the fusion of new technology with instructional work. Computer Supported Cooperative Work (CSCW) 17 (1), 35-62. 
was important to see them in relation to the initial 'task'. This is akin to Lynch's (1985, p.55) observation concerning activities in research laboratories:

to achieve a sensibility of the scene as something other than a spectacle, required the particular of the operations to be sensible in terms of their 'place' within a project.

The organisation of tasks is tied to what we might call teachers' 'how much is enough?' question of determining how much to tell pupils, before letting them work on their own. That is to say, in setting a task, teachers need to strike a balance between what to tell pupils and what to rely on pupils to already know or easily find out for themselves. In particular, teachers may not want to specify what pupils should do in every detail, in order to provide enough room for pupils to do 'more' than they were asked to do, since it is through this 'more' that pupils can demonstrate that they have understood the task and its objectives. In other words, when setting a task, teachers need to give pupils enough so that they can get started while still leaving room so that the task can be used as a basis to assess what pupils will have done. Setting tasks then needs to be organised in such a way that teachers can see pupils' own achievements (which means, for example, that in the university context students are not just 'reproducing the lecture'). Teachers want pupils to see what is educationally valuable about a certain activity. In turn, pupils should demonstrate that they have understood what the aim of a particular task is by doing the task in an 'appropriate’ way.

In this sense, the specification of an assortment of things to do and specifications of how to do some of them provides a baseline for monitoring the pupils' subsequent activities. That is, the teacher's instructions function like a 'members' measurement system' (see, 
e.g., Sacks, 1988/9). Tasks also work as an 'explicative transaction’ (see, e.g., Pollner, 1979; Watson and Sharrock, 1987). That is to say, what pupils subsequently do can be seen in terms of the initial specification of the task, where the match between what the pupils have been told to do may be indicative of their success or failure in understanding the initial instructions and their ability to do more than they have been told.

This kind of issue of leading in the right direction without giving away the answer/solution is not unique to teaching and learning, but can be found in other professional activities. For example, Schegloff (1963) describes the job of a psychiatrist as getting the patient to see situations in the 'correct' way (i.e., according to the psychiatric theory), which means that patients have to learn to describe situations in terms of that theory. Sociologists who use interviews face a similar issue. The interviewer has to provide the interviewee with a research interest (e.g., 'race') without specifying what exactly the interviewee should say about that topic (cf., Anderson, 1977, pp. G1-G2). In the classroom, the teacher needs to achieve a balance between, on the one hand, saying 'enough' in order for pupils to know what to do and why they are doing it, and, on the other hand, saying 'not too much' so there is still space for the pupils to demonstrate that they have understood the task.

Of course, teachers do not simply set a task and then let pupils 'get on with it'. Rather, teachers review the progress of pupils. Thus teacher's will 'make rounds' in order to diagnose what pupils are doing right and where they are going wrong. This will allow the teacher to identify matters that pupils did not pick up in her instruction session, as well as matters that the teacher did not make plain enough or possibly overlooked. Reviewing also allows the teacher to avoid the 'too late' problem (Sharrock and Button, 1997), i.e., 
the predicament of discovering mistakes too late in the process and either not being able to fix the mistake or having to redo a lot of completed work. The teacher can locate just what the misunderstanding is and where it occurs.

Saying that pupils can be held accountable with respect to the initial formulation of the task, is not to say that the specification of what pupils should do never changes. The teacher wants to give pupils enough resources to get started, but very often the teacher although having some educational goal in mind, does not have a definitive plan for getting there. Therefore, the teacher will wait and see what the pupils will do with her initial instructions and make adjustments according to what she deems satisfactory and unsatisfactory. Although it is the teacher who initially sets up the tasks, the task is in a sense achieved through the subsequent work of pupils, which is in turn 'okayed' or corrected by the teacher. The teacher can thus be seen as systematically ad hocing her way through lessons (cf., Anderson, 1979, p.54) by flexibly responding to what pupils do with her initial specification of the task ${ }^{9}$. This was particularly the case here, since in a sense the teacher was herself (covertly) discovering what one could do with the storyboarding software.

The specific form of the task evolved over time. For example, how much of the scene the pupils should do, how much time they will have to do this, which features of the software they should use to do so, and so on, all changed during the course of the lessons. What is

\footnotetext{
${ }^{9}$ This is not meant as a criticism, but as comment on the teacher's ability to deal with problems as and when they arose in the following of the task.
}

Greiffenhagen, C. (2008). Unpacking tasks: the fusion of new technology with instructional work. Computer Supported Cooperative Work (CSCW) 17 (1), 35-62. 
remarkable is just how unproblematic this seems to be: no pupil ever cries out "but you didn't tell us earlier”. Nor are the teacher's announcements marked as something out-ofthe-ordinary, which suggests that it is expected that 'the' task will change (not fundamentally, but in various ways). 'The' task is continuously and collaboratively 'worked up’ (cf., Garfinkel et al., 1981). This is done not just through announcements to the whole-class but also when the teacher is reviewing individual pupils' work. A task might start off loosely, but is given a more concrete shape during its production. Douglas Macbeth (personal communication) expressed this beautifully:

It's as though we're doing compass readings to figure out where we are in the landscape of the task, and it ends up giving the thing a shape (reflexively, and always revisable). The assessments are deciding what the task is, in the course of its production.

Tasks provide a frame in which pupils can move, where this frame is progressively specified: certain contingencies are not known in advance, but will be dealt with when they are encountered in the process of doing the activity.

\section{Conclusion}

This paper has approached the phenomenon of the integration of task, technology, and activities through a methodological eclecticism. I have argued that the historical and serendipitous co-incidence of interests between conversation/interaction analysis and CMC produced a range of exemplary work. Nevertheless, the analytic work in question for the most part involved a set of known problems with (more or less) known technology. Observational work is not always done in this context. Sometimes, and I suggest that the context described above is one of those times, a new technology is such that an 
evaluation through observation requires attention to such matters as the purposes associated with that technology. Consequently, the way in which those purposes were managed and negotiated in and through the practical business of getting through a lesson then became a vehicle for the close observation and analysis of work sequences normally associated with conversation and interaction analytic work. Even there, the kinds of common sense understanding of what it means to be engaged in a lesson, as well as the way in which actions were sequenced, was necessary.

Hopefully, then, this modest study provides some lessons itself. They concern the character of enquiry. We have seen that teachers and pupils are engaged in a job of work, where the measure of their effectiveness is the purposes they attend to, and the ways they transform them into practical tasks. These purposes have to do with the conduct of an orderly and well-structured lesson, where interventions are made in a timely and relevant way; the explicit learning of a technology; an orientation to a wider context (that of the SATs), beliefs about 'good' educational practice, and so on. It also seems to me that attention to these things (the purposes of work activity in the context in which it is to be found, orderliness, the construal of 'good' work, 'timely' intervention, and so on) are features we might expect to see in a wide variety of work contexts.

Similarly, the idea of a 'fit' between the technology, purpose and practical working turns out to be relevant here as elsewhere. We asked the teacher after the final lesson for her opinion of kar2ouche:

As I previously explained [...] what this really does is it simply takes something they already do and makes it more technical, more fun. This is the first time I've done Macbeth but before, 
with Romeo and Juliet, what I did was what I did this time. I showed the students three productions of Romeo and Juliet. In this case we watched Macbeth. I then got them to produce their own storyboards on paper. So what I do is I photocopy the script of the scenes I want done onto big A3 paper and then suggest they design their own storyboard on paper. How would they have people move? What would they look like? All this enables them to do is to take that and put it into 3-D and make it more fun. This has brought it more alive for them. (Interview 16/3/2001)

Educational goals, task, and the technology were thus intertwined in various ways (cf. Hutchby, 2001, LeBaron, 2002). Technologies might well restrict what teachers (and others at work) can do, but skilful marriage of the technology with other activities, in accordance with the teacher's assumptions about how lessons should proceed, culminated in a series of 'good lessons about Macbeth'. A sense of purpose and ongoing construal of the task determined which features of the technology were employed. In these lessons, the teacher's emphasis on the importance of the writing in the thought bubbles and caption box (whereas pupils seemed to focus more naturally on the pictures) demonstrates the fact that the task has to be understood in relation to the educational objectives the teacher wanted to achieve.

One possible advantage of this technology (and the reason for it now being a relatively successful commercial product) is the fact that the original design specification of the educationalist was produced with a knowledge of context, and with an 'openness' that allowed for flexible use. The technology fitted into existing teaching and learning practices. I leave the last word to the classroom teacher: "No disrespect but Kar2ouche is not a new idea. It's simply a new format, which is lovely.” 


\section{Acknowledgements}

I am most indebted to the two teachers who helped me with this project by allowing me to spend an extensive period of time in their classrooms. Without their generosity this study could not have been conducted. I would also like to thank Rod Watson, Dave Randall, Wes Sharrock, Jac Eke, and two anonymous reviewers for helpful comments and criticisms on earlier versions of this paper. The work on this paper was partly supported by a British Academy Postdoctoral Fellowship.

\section{References}

Anderson, D. C. (1979). The formal basis for a contextually sensitive classroom agenda. Instructional Science 8 (1), 43-65.

Anderson, R. J. (1977). Research activities and professional practice. Analytic Sociology 1 (1), F10-G12.

Annett, J. and N. A. Stanton (Eds.) (2000). Task Analysis. London: Taylor \& Francis.

Blomberg, J. and R. Trigg (2000). Co-constructing the relevance of work practice for CSCW design. Occasional Papers from the Work Practice Laboratory 1 (2). University of Karlskrona, Sweden.

Button, G. (Ed.) (1993). Technology in Working Order: Studies of work, interaction, and technology. London: Routledge.

Diaper, D. (Ed.) (1989). Task Analysis for Human-Computer Interaction. Chichester: Ellis Horwood.

Dourish, P. (2006). Implications for design. In Proceedings of CHI 2006 (Montreal, Canada), pp. 541-550.

Dourish, P. and G. Button (1998). On "technomethodology": foundational relationships between ethnomethodology and system design. Human-Computer Interaction 13 (4), 395-432.

Garfinkel, H. (Ed.) (1986). Ethnomethodological Studies of Work. London: Routledge.

Garfinkel, H., M. Lynch, and E. Livingston (1981). The work of a discovering science construed with materials from the optically discovered pulsar. Philosophy of the Social Sciences 11 (2), 131-158.

Gibson, R. (1998). Teaching Shakespeare. Cambridge: Cambridge University Press.

Heap, J. L. (1988). On task in classroom discourse. Linguistics and Education 1, 177198.

Greiffenhagen, C. (2008). Unpacking tasks: the fusion of new technology with instructional work. Computer Supported Cooperative Work (CSCW) 17 (1), 35-62. 
Heap, J. L. (1989a). Collaborative practices during word processing in a first grade classroom. In C. Emihovich (Ed.), Locating Learning: Ethnographic Perspectives on Classroom Research, pp. 263-288. Norwood, NJ: Ablex.

Heap, J. L. (1989b). Sociality and cognition in collaborative computer writing. In D. Bloome (Ed.), Classroom and Literacy, pp. 135-157. Norwood, NJ: Ablex.

Heap, J. L. (1992). Seeing snubs: an introduction to sequential analysis of classroom interaction. The Journal of Classroom Interaction 27 (2), 23-28.

Heath, C., M. Sanchez Svensson, J. Hindmarsh, P. Luff, P., and D. vom Lehn (2002). Configuring awareness. Computer Supported Collaborative Work (CSCW) 11 (3-4), 317-347.

Hemmings, T., D. Randall, L. Marr, and D. W. Francis (2000). Task, talk and closure: situated learning and the use of an 'interactive' museum artefact. In Hester and Francis (2000a), pp. 223-244.

Hester, S. and D. W. Francis (Eds.) (2000a). Local Educational Order: Ethnomethodological Studies of Knowledge in Action. Amsterdam: John Benjamin.

Hester, S. and D. W. Francis (2000b). Ethnomethodology, conversation analysis, and 'institutional talk'. Text 20 (3), 391-413.

Heyman, R. D. (1986). Formulating topic in the classroom. Discourse Processes 9 (1), 37-55.

Hutchby, I. (2001). Technologies, texts and affordances. Sociology 35 (2), 441-456.

Jordan, B. and A. Henderson (1995). Interaction analysis: foundations and practice. Journal of the Learning Sciences 4 (1), 39-103.

Koschmann, T., and C. LeBaron (2003). Reconsidering common ground: examining Clark's contribution theory in the OR. In Proceedings of ECSCW'03 (Helsinki, Finland), pp. 81-98.

LeBaron, C. D. (2002). Technology does not exist independent of its use. In T. Koschmann, R. Hall, and N. Miyake (Eds.), CSCL 2: Carrying Forward the Conversation, pp. 433-439. Hillsdale, NJ: Lawrence Erlbaum.

Lynch, M. (1985). Art and Artifact in Laboratory Science. London: Routledge.

Lynch, M. (1993). Scientific Practice and Ordinary Action. Cambridge: Cambridge University Press.

Lynch, M. and D. H. Macbeth (1998). Demonstrating physics lessons. In J. G. Greeno and S. V. Goldman (Eds.), Thinking Practices in Mathematics and Science Learning, pp. 269-297. Mahwah, NJ: Lawrence Erlbaum.

Macbeth, D. H. (1990). Classroom order as practical action: the making and un-making of a quiet reproach. British Journal of Sociology of Education 11 (2), 189-214.

Macbeth, D. H. (1991). Teacher authority as practical action. Linguistics And Education 3 (4), 281-313.

Macbeth, D. H. (1992). Classroom 'floors': material organizations as a course of affairs. Qualitative Sociology 15 (2), 123-150.

Greiffenhagen, C. (2008). Unpacking tasks: the fusion of new technology with instructional work. Computer Supported Cooperative Work (CSCW) 17 (1), 35-62. 
Macbeth, D. H. (1994). Resuming: the final contingency of reproach. Qualitative Studies in Education 7 (2), 135-154.

Macbeth, D. H. (2000). Classrooms as installations: direct instruction in the early grades. In Hester and Francis (2000a), pp. 21-71.

Macbeth, D. H. (2003). Hugh Mehan's 'Learning Lessons' reconsidered: on the differences between the naturalistic and critical analysis of classroom discourse. American Educational Research Journal 40 (1), 239-280.

McHoul, A. W. and D. R. Watson (1984). Two axes for the analysis of 'commonsense' and 'formal' geographical knowledge in classroom talk. British Journal of Sociology of Education 5 (3), 281-302.

Mehan, H. (1989). Microcomputers in classrooms: educational technology or social practice? Anthropology and Education Quarterly 20 (1), 4-22.

Payne, G. C. F. (1976). Making a lesson happen: an ethnomethodological analysis. In M. Hammersley and P. Woods (Eds.), The Process of Schooling: A Sociological Reader, pp. 33-40. London: Routledge.

Payne, G. C. F. (1979). Some Aspects of the Social Organisation of Classroom Talk. Ph.D. thesis, Manchester University.

Payne, G. C. F. and E. C. Cuff (Eds.) (1982). Doing Teaching: The Practical Management of Classrooms. London: Batsford.

Payne, G. C. F. and D. Hustler (1980). Teaching the class: the practical management of a cohort. British Journal of Sociology of Education 1 (1), 49-66.

Pollner, M. (1979). Explicative transactions: making and managing meaning in traffic court. In G. Psathas (Ed.), Everyday Language: Studies in Ethnomethodology, pp. 227-255. New York: Irvington.

Randall, D., L. Marr, and M. Rouncefield (2001). Ethnography, ethnomethodology and interaction analysis. Ethnographic Studies 6, 31-43.

Randall, D., R. Harper, and M. Rouncefield, M. (forthcoming). Ethnography in design. London: Springer.

Ruhleder, K. and B. Jordan (1999). Meaning making across remote sites: how delays in transmission affect interaction. In Proceedings of ECSCW'99 (Copenhagen, Denmark), pp. 411-429.

Sacks, H. (1972). On the analyzability of stories by children. In J. J. Gumperz and D. H. Hymes (Eds.), Directions in Sociolinguistics: The Ethnography of Communication, pp. 325-345. New York: Holt, Rinehart and Winston.

Sacks, H. (1988/89). On members' measurement systems. Research on Language and Social Interaction 22, 45-60.

Sacks, H. (1992). Lectures on Conversation (Edited by G. Jefferson). Oxford: Blackwell.

Schegloff, E. A. (1963). Toward a reading of psychiatric theory. Berkeley Journal of Sociology 8, 61-91.

Schmidt, K. (2002). The problem with 'awareness'. Computer Supported Cooperative Work (CSCW) 11 (3-4), 285-298.

Greiffenhagen, C. (2008). Unpacking tasks: the fusion of new technology with instructional work. Computer Supported Cooperative Work (CSCW) 17 (1), 35-62. 
Shapiro, D. (1996). Ferrets in a sack? Ethnographic studies and task analysis in CSCW. In D. Shapiro, M. Tauber, and R. Traunmüller (Eds.), The Design of Computer Supported Cooperative Work and Groupware Systems, pp. 309-330. Amsterdam: Elsevier.

Sharrock, W. W. (1974). On owning knowledge. In R. Turner (Ed.), Ethnomethodology: Selected Readings, pp. 45-53. Harmondsworth: Penguin Education.

Sharrock, W. W. and G. Button (1997). Engineering investigations: practical sociological reasoning in the work of engineers. In G. C. Bowker, S. L. Star, W. Turner, and L. Gasser (Eds.), Social Science, Technical Systems, and Cooperative Work: Beyond the Great Divide, pp. 79-104. Mahwah, NJ: Lawrence Erlbaum.

Sharrock, W. W. and D. R. Watson (1985). 'Reality construction' in L2 simulations. System 13 (3), 195-206.

Sheridan, T. B. (1997). Task analysis, task allocation and supervisory control. In M. Helander, T. K. Landauer, and P. Prabhu (Eds.), Handbook of Human-Computer Interaction (Second ed.), pp. 87-105. Amsterdam: Elsevier.

Turner, R. (1972). Some formal properties of therapy talk. In D. Sudnow (Ed.), Studies in Social Interaction, pp. 367-396. New York: Free Press.

Watson, D. R. and W. W. Sharrock (1987). Some social-interactional aspects of a business game for special purposes in the (L2) teaching of English. In D. Crookall, C. S. Greenblat, A. Coote, J. H. G. Klabbers, and D. R. Watson (Eds.), SimulationGaming in the Late 1980s. Proceedings of the International Simulation and Gaming Association's 17th International Conference, pp. 177-186. Oxford: Pergamon.

Greiffenhagen, C. (2008). Unpacking tasks: the fusion of new technology with instructional work. Computer Supported Cooperative Work (CSCW) 17 (1), 35-62. 
Page 44 of 44

\section{Appendix}

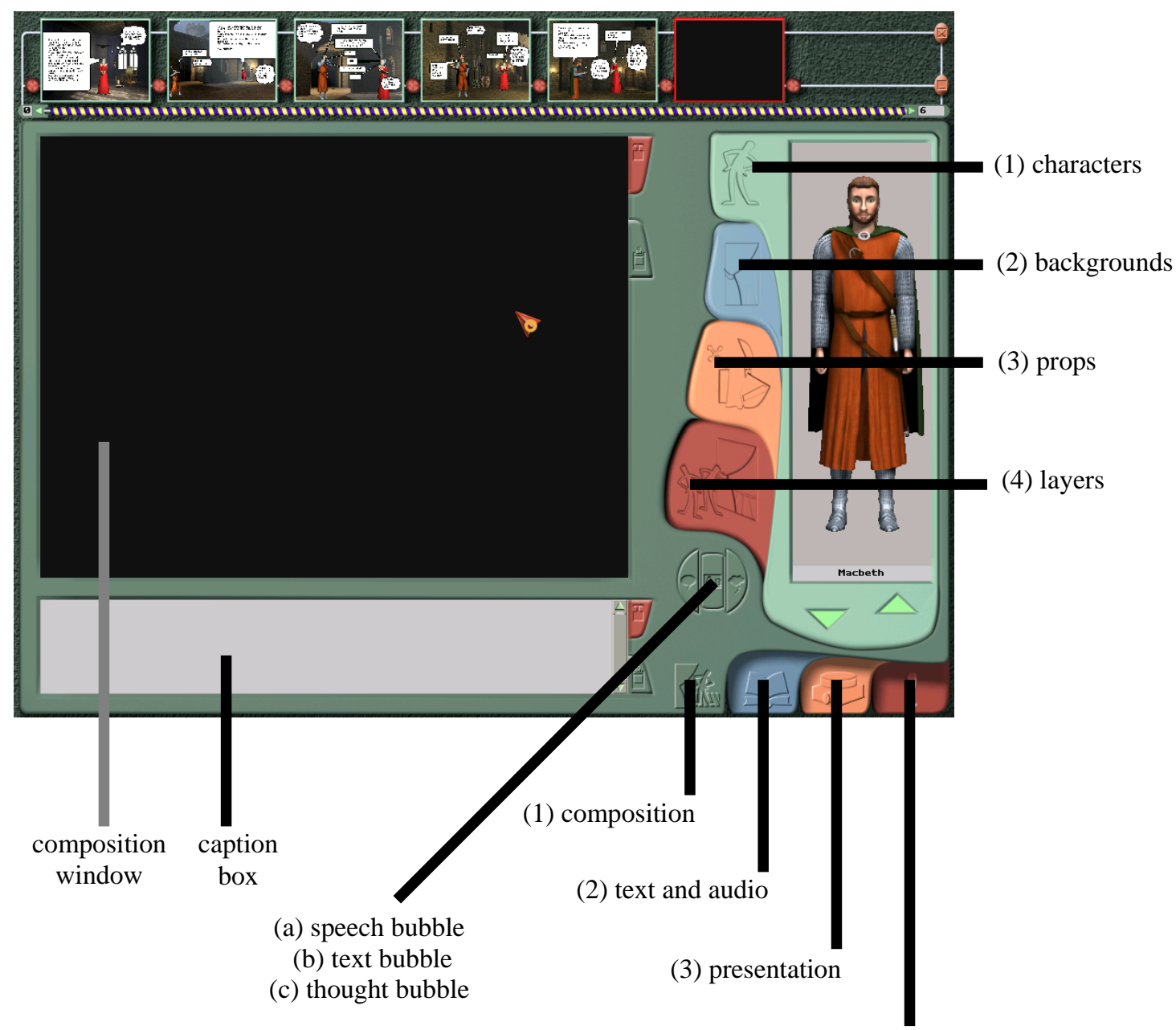

(4) utilities

Greiffenhagen, C. (2008). Unpacking tasks: the fusion of new technology with instructional work. Computer Supported Cooperative Work (CSCW) 17 (1), 35-62. 